\title{
A saúde coletiva na perspectiva dos fundadores: espaço de convergência para heterogeneidade
}

\author{
Collective health from the founders' perspective: room for \\ convergence and heterogeneity
}

La salud colectiva desde la perspectiva de los fundadores: espacio de convergencia para la heterogeneidad

\begin{abstract}
Vieira-da-Silva LM. O campo da saúde coletiva: gênese, transformações e articulações com a reforma sanitária brasileira. Rio de Janeiro: Editora Fiocruz/Salvador: EDUFBA; 2018. 269 p. ISBN 978-85-232-1788-4.
\end{abstract}

doi: 10.1590/0102-311X00209519

O atual contexto econômico, social e político brasileiro exige que a Saúde Coletiva conheça e ressignifique sua trajetória para melhor atuação daqueles que a escolheram para atuação profissional. Nesse âmbito, a EDUFBA e a Editora Fiocruz apresentam o livro O Campo da Saúde Coletiva: Gênese, Transformações e Articulações com a Reforma Sanitária Brasileira, de autoria da professora e pesquisadora da Universidade Federal da Bahia, Ligia Maria Vieira-da-Silva, com participação de outros quatro pesquisadores da referida instituição.

O livro é relevante para a Saúde Coletiva por discutir os fundamentos da área no Brasil, desenvolvendo uma, entre outras, possibilidades para apresentar historicamente esse processo. A escrita dá potência às informações coletadas por construir a interface entre reflexões teóricas e narrativas individuais que produzem sentido histórico ao serem unidas e apresentadas coletivamente.

Em sete capítulos, a autora discorre sobre questões importantes para a compreensão dos cenários políticos, econômicos e institucionais para o desenvolvimento da Saúde Coletiva. No primeiro, são explicitadas as condições históricas, inicialmente baseadas em filantropia e influência de instituições internacionais, o que ajudou a modificar os processos formadores sobre saúde pública nas universidades. No segundo capítulo, há discussão acerca das diferentes espécies de capitais envolvidos na gênese da Saúde Coletiva, quais sejam: científico, burocrático, burocrático universitário, político, político-partidário, institucionais e sociais.

Além do conceito de capitais, a autora também se apoia no conceito de campo desenvolvido por Bourdieu 1, para explicar o processo em construção do campo da Saúde Coletiva. Ela destaca a importância de algumas universidades brasileiras para consolidação do campo, as quais continuam, após décadas, ocupando lugar de destaque na formulação intelectual e formação de profissionais.

No terceiro e quarto capítulos, a autora explicita o cenário formado por diversos atores com perspectivas convergentes e divergentes para a construção da Saúde Coletiva. Discute, também, a necessidade de tomada de decisão deles para a defesa de um campo afeito à heterogeneidade de espaços, ideias e agentes. Essa é uma característica fortalecida ao longo do tempo e ainda basilar para o campo ${ }^{2}$, considerando os diferentes locus de atuação, bem como as distintas áreas de formação de seus integrantes. 
A autora nos remete à influência da Associação Brasileira de Saúde Coletiva (Abrasco) para a indução de importantes encontros e aproximações entre os que buscavam um espaço para convergência de ideias em torno da construção de uma nova "medicina social". Salienta-se que a concatenação entre teoria, prática, pesquisa e ensino, potencializou a formação dos profissionais no campo, o que fortalece a perspectiva da Saúde Coletiva como corrente de pensamento, movimento social e prática teórica 3.

Os pesquisadores Sandra Garrido de Barros, Jamacy Souza Costa e Gerluce Alves Pontes da Silva participaram da elaboração do quinto capítulo, em que se explicita o espaço da Saúde Coletiva, especialmente o científico, entre a criação da Abrasco, em 1979, até a avaliação da área pela Coordenação de Aperfeiçoamento de Pessoal de Nível Superior (Capes), em 2009. Apresenta-se um panorama da Saúde Coletiva com a classificação dos programas de pós-graduação pela Capes, formação dos docentes (profissões e instituições) e principais temas estudados pelos docentes/pesquisadores.

Jairnilson Silva Paim escreveu o sexto capítulo, que discute a Reforma Sanitária Brasileira mediante as narrativas dos "intelectuais fundadores”. A sua abordagem é inovadora por apresentar a perspectiva dos fundadores, ao tempo em que realiza reflexões teóricas importantes para discussões e consolidação do campo no âmbito da pós-graduação. Destaca, em concordância com outros autores 4,5, a contribuição das Ciências Sociais para a discussão sobre as questões de saúde na América Latina e como isso influenciou a inserção dessa área disciplinar entre as bases da Saúde Coletiva.

No último capítulo, a autora convida os leitores ao debate por intermédio do seguinte questionamento: Saúde Coletiva é um espaço de rela- ções ou um campo em consolidação? Sem apresentar uma resposta a essa questão e ampliando o debate, a autora foca a interação entre os polos do mercado, a burocracia estatal e a Saúde Coletiva universitária. Outrossim, é explicitado o desenvolvimento contínuo dos processos para a construção das diversas identidades presentes no campo, influenciadas pelo contexto da formação universitária em saúde e do sistema de saúde brasileiro.

Nos apêndices do livro, são apresentadas notas metodológicas e esclarecimento de que a obra é produto de uma pesquisa desenvolvida com 31 entrevistados que concederam as narrativas individuais para a sua construção. Trata-se de fundadores da Saúde Coletiva que qualificaram o conhecimento acerca dos meandros constitutivos do campo e discutiram os principais desafios vivenciados no passado e na contemporaneidade.

É possível afirmar que o livro é voltado especialmente aos acadêmicos da graduação e pósgraduação em saúde (coletiva), por denotar a história do campo e relacionar uma matriz teórico-conceitual fundamental das ciências sociais com a experiência daqueles que construíram e ainda constroem caminhos no cotidiano da Saúde Coletiva.

\author{
Antonio Rodrigues Ferreira Júnior 1 \\ Nelson Filice de Barros 2 \\ 1 Universidade Estadual do Ceará, Fortaleza, Brasil. \\ 2 Universidade Estadual de Campinas, Campinas, Brasil \\ arodrigues.junior@uece.br
}




\section{Colaboradores}

Ambos os autores elaboraram a resenha.

\section{Informações adicionais}

ORCID: Antonio Rodrigues Ferreira Júnior (00000002-9483-8060); Nelson Filice de Barros (00000002-5404-1516).
1. Bourdieu P. As regras da arte: gênese e estrutura do campo literário. Lisboa: Editorial Presença; 1996.

2. Osmo A, Schraiber LB. O campo da Saúde Coletiva no Brasil: definições e debates em sua constituição. Saúde Soc 2015; 24 Suppl 1:20518.

3. Nunes EV. Saúde coletiva: história de uma ideia e de um conceito. Saúde Soc 1994; 3:5-21.

4. Ianni AMZ, Spadacio C, Barboza R, Alves OSF, Viana SDL, Rocha AT. As Ciências Sociais e Humanas em Saúde na ABRASCO: a construção de um pensamento social em saúde. Cad Saúde Pública 2014; 30:2298-308.

5. Nunes EV. A trajetória das ciências sociais em saúde na América Latina: revisão da produção científica. Rev Saúde Pública 2006; 40(N Spe):64-72. 